\title{
Standardization of Valeriana officinalis L. rhizome and roots cultivating in different regions of Armenia (Rhizomata cum Radicibus valerianae officinalis L.).
}

\author{
Hovhannisyan VG*, Chichoyan NB \\ Department of Pharmacognosy, Yervan State Medical University after M. Heratsi, Yerevan, Armenia
}

\begin{abstract}
Valerian is the most popular plant in medicine. It has been cultivated from ancient times and established itself as a profitable culture. The underground part of valerian is the source of commonly used sedatives, especially in chronic diseases. This plant is still the subject of considerable research aimed at establishing the chemical and pharmacological basis of the activity which has been clearly shown in a number of animal and clinical studies. The purpose of the study was to standardize the raw material $f$ Valeriana officinalis L. cultivated in different regions of Armenia (Aparan, Ashotavan). As a material served rhizome with roots, obtained from the Valeriana officinalis L., cultivated in different regions of Armenia (Aparan, Ashotavan) in the second half of September in 2015. The commodity analysis of the raw material (volatile oil, extract, moisture, total ash) was carried out according to the requirements of WHO. The microscopic analysis was carried out with triocular electronic "Micros" microscope $(10 \times 40)$ and Olympus Digital C-3000 Zoom camera. The qualitative analysis of essential oil was carried out by GC-MS method. The research was carried out on gas chromatograph with a mass-selective spectrometer "BrukerDaltonik" (EM-640S). Unlike the pre-mountainous zone conditions of Aparan, the latter proves that in the mountainous zone conditions of Ashotavan, the plant has a developed mechanical tissue, which is displayed with the formation of sclereids. The existence of drouses is also typical to a preparation, which is an anatomical differentiative feature for the raw material harvested from Ashotavan. In the result of the research confined the quality indices of valerian cultivated in Ashotavan and Aparan (volatile oil, the total of extracts, moisture, and total ash). The analysis showed that in volatile oil of Valerian climatized in Ashotavan and in Aparan the prevailing was bornyl acetate, the quantities of which were $55.2 \%$ and $90.7 \%$.
\end{abstract}

Keywords: Aparan, Ashotavan, Valeriana officinalis L., Microscopical analysis, Volatile oil, Gas chromatography mass spectroscopy method, Bornyl acetate.

Accepted on December 12, 2018

\section{Introduction}

Valerian is the most popular plant in medicine. It has been cultivated from ancient times and established itself as a profitable culture. The underground part of valerian is the source of commonly used sedatives, especially in chronic diseases. Herbal remedy is considered as an alternative and complementary treatment of insomnia which has been reflected in many ethnobotanical investigations [1-9]. In the $2^{\text {nd }}$ century $\mathrm{AD}$, for example, the prominent ancient Greek physician Galen prescribed valerian for insomnia [10-16].

Valerian is a nutraceutical preparation from the roots of Valeriana officinalis $\mathrm{L}$. and related species that is recommended for relief of tension, anxiety and insomnia. The greatest biological efficacy of valerian has been correlated with freshly harvested and carefully dried root preparations and with the iridoid alkaloid and sesquiterpene content of these preparations [17-22]. Valeriana officinalis L. is the species most commonly used in northern Europe and still retains its official pharmacopoeial status although it is most commonly encountered as an ingredient of herbal medicines. This plant is still the subject of considerable research aimed at establishing the chemical and pharmacological basis of the activity has been clearly shown in a number of animal and clinical studies [23-26].

The purpose of the study was to standardize the raw material $\mathrm{f}$ Valeriana officinalis L. cultivated in different regions of Armenia (Aparan, Ashotavan).

\section{Materials and Methods}

As a material served rhizoma cum radicibus (ERE 193404), obtained from the Valeriana officinalis L., cultivated in different regions of Armenia (Aparan, Ashotavan) in the second half of September in 2015. 
The processing of herbal raw materials was carried out in accordance with WHO guidelines governing the harvesting process [27].

The commodity analysis of the raw material (volatile oil, extracts, moisture, total ash) was carried out according to the requirements of WHO [28].

The microscopic analysis was carried out with triocular electronic "Micros" microscope $(10 \times 40)$ and Olympus Digital C-3000 Zoom camera. The qualitative analysis of essential oil was carried out by GC-MS method. The research was carried out on gas chromatograph with a mass-selective spectrometer "BrukerDaltonik" (EM-640S).

Helium was used as a gas carrrier, the flow of the injector was $30 \mathrm{ml} / \mathrm{min}$. An OPTIMA-FEAP capillary column (DF: 0.25 ; ID: 250) was used, the temperature gradient $40^{\circ} \mathrm{C}(1 \mathrm{~min})$ to $200^{\circ} \mathrm{C}$, heated up to $200^{\circ} \mathrm{C}$, scanning at $30-400 \mathrm{~m} / \mathrm{z}$. The compounds were identified according to NIST (National Institute of Standard and Technology-Mass Spectrometry) data.

\section{Results and Discussion}

The results of the microscopic analysis showed that on the preparation of the raw material of Valeriana officinalis L. cultivated in Aparan rectangular epiblem cells with thickened walls are seen. Large parenchyma cells filled with starch granules are visible and a large number of essential oil globules of hypodermis are expressed. (Figures 1 and 2).

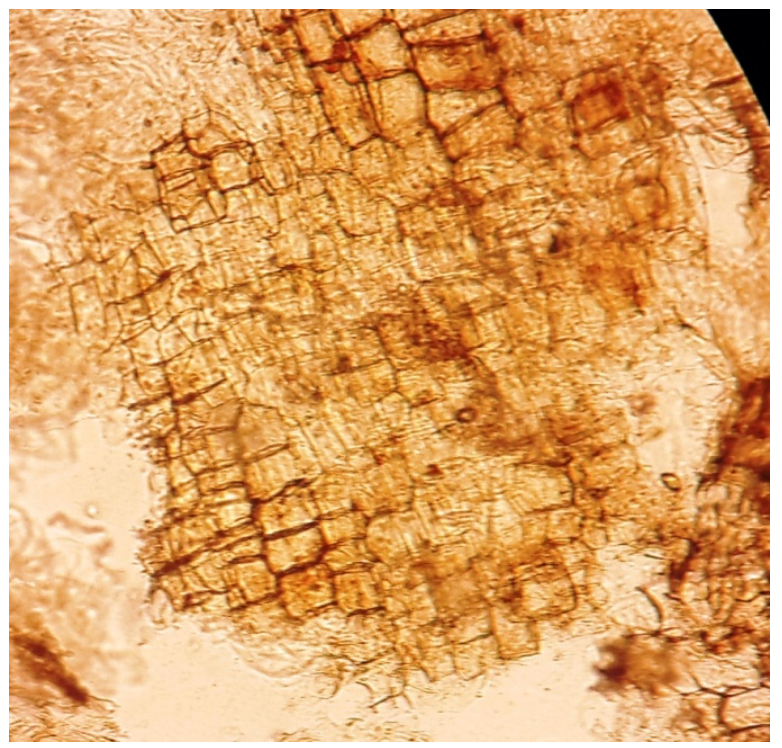

Figure 1. Valeriana officinalis root transverse section (Aparan). aepiblem cells with thickened walls.

Conducting bundle with netlike vessels and parenchyma jelly starch granules are well expressed (Figure 3).

Stone cells are rare seen in the preparation of the raw material of valerian grown in Aparan (Figure 4).

The results of the preparation analysis of Valeriana officinalis L. cultivated in Syunik (Ashotavan) showed that in the cells of the hypoderm were well-expressed the globules of essential oil
(Figures 5a and 5b), starch granules and simple unicellular trichome (Figure 6).

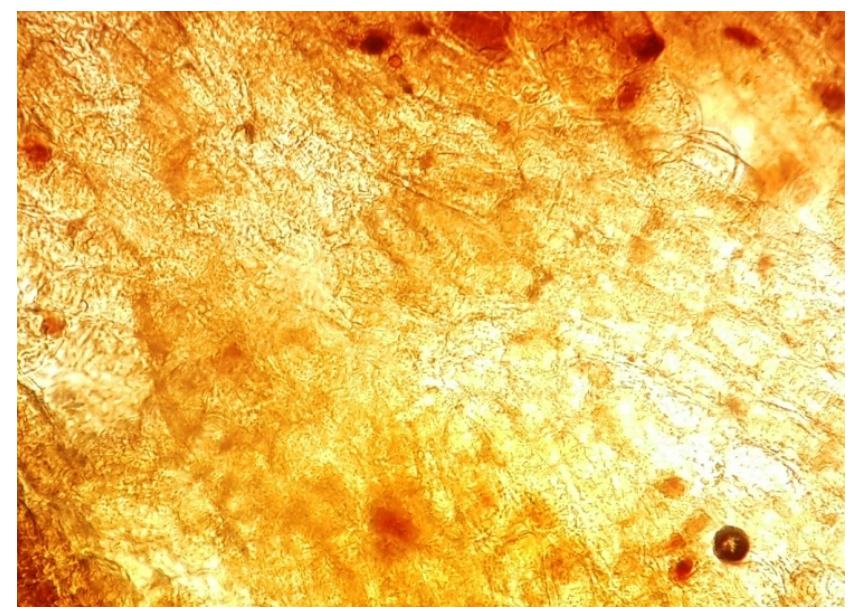

Figure 2. Valeriana officinalis root transverse section (Aparan). a and b-essential oil globules of hypodermis.

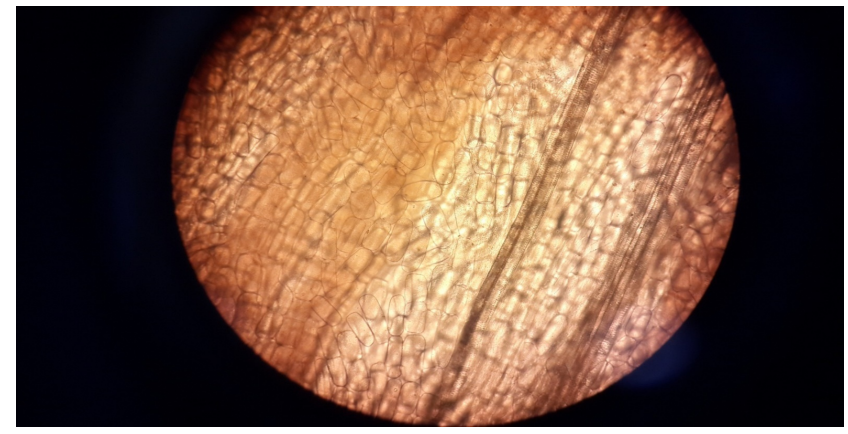

Figure 3. Valeriana officinalis root transverse section (Aparan). a and b-netlike vessels, c-jelly starch granules.

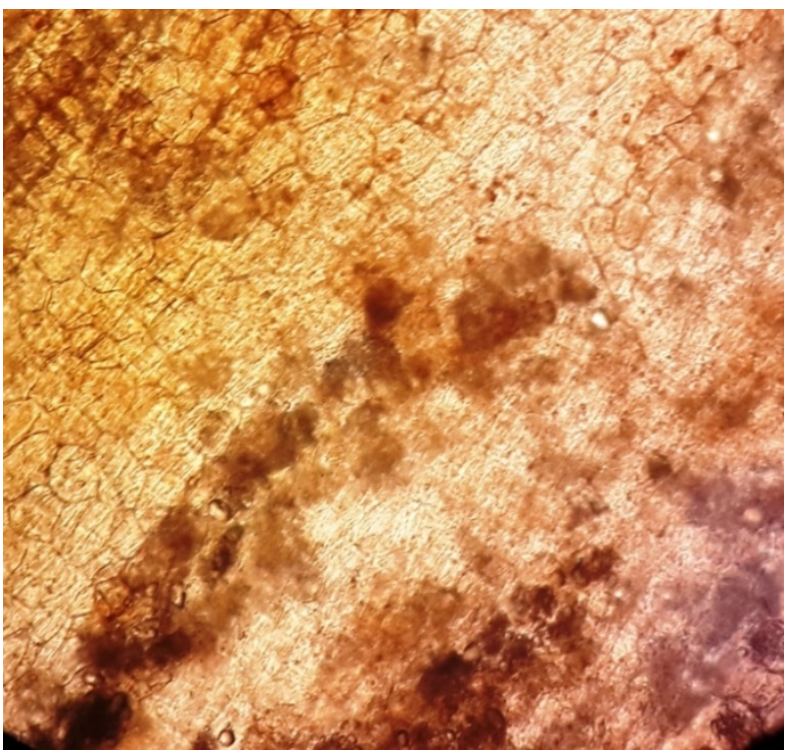

Figure 4. Valeriana officinalis rhizome transverse section (Aparan). a and b-stone cells.

Conducting system of a root is well expressed with thickened net-like vessels, which unlike the raw material of Aparan, in this case here and there are well seen thickened 
parenchymatous stone cells (Figures 7a and 7b). Unlike the pre-mountainous zone conditions of Aparan, the latter proves that in the mountainous zone conditions of Ashotavan, the plant has a developed mechanical tissue, which is displayed with the formation of sclereids.

The existence of drouses is also typical to a preparation, which is an anatomical differentiative feature for the raw material harvested from Ashotavan (Figure 8).

Recorded anatomical differentiative features prove that all these raw materials got morphological anatomical features stipulated by the influence of climatic conditions, can play a serious role in the primary standardisation process of a raw material.

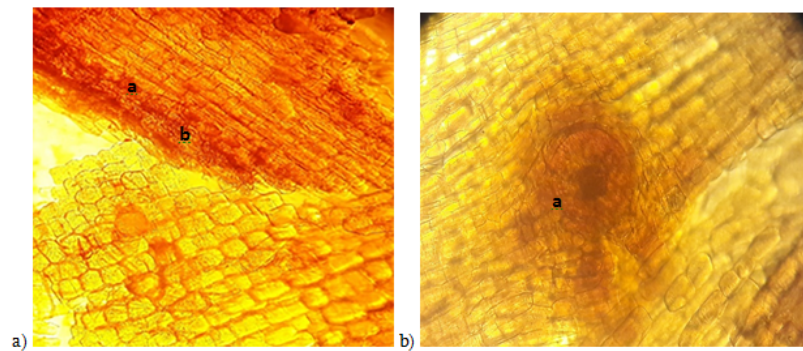

Figure 5. a) Valeriana officinalis rhizome transverse section (Ashotavan), a and b-essential oil globules of hypodermis. b) Valeriana officinalis rhizome transverse section (Ashotavan). aessential oil globules of hypodermis.

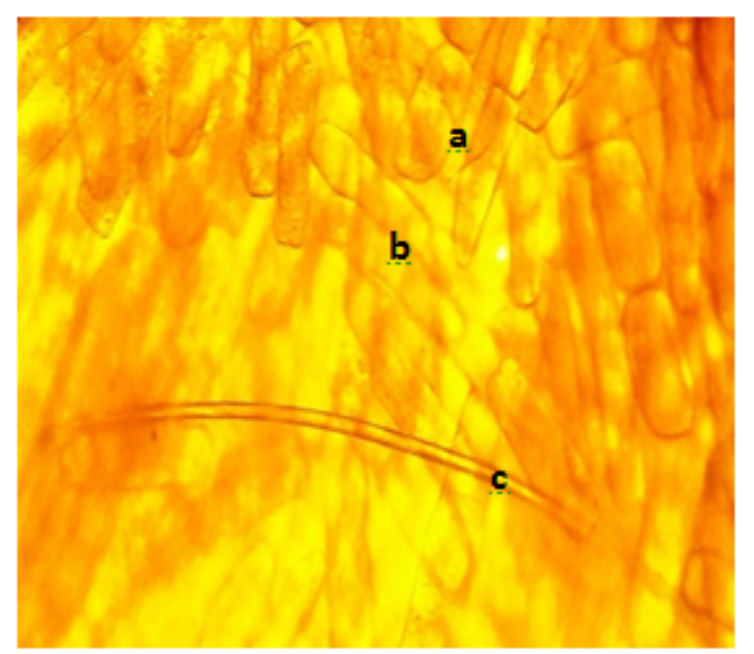

Figure 6. Valeriana officinalis rhizome transverse section (Ashotavan). A and b-jelly starch granules. c-simple unicellular trichome.
The outcome of the essential oil according to European pharmacopeia is considered the main criteria of good quality for the raw material of Valeriana officinalis L., where the amount of the essential oil mustn't be less than $5 \mathrm{ml} / \mathrm{kg}$. According to the results of our investigation the outcome of the essential oil obtained from Valeriana officinalis harvested from Aparan is $1.22 \%$. Whereas the raw material harvested from Ashotavan was $0.98 \%$, which completely corresponds to the European pharmacopeia indices confirmed for Valeriana officinalis L. [29].

As the results of the research showed, the total of extracted substances was $29 \%$ in the harvested raw material of Aparan, and in the raw material of Ashotavan-27\%, which also conformed the quality indices for the raw material of European pharmacopeia (not less than 25\%) [29].
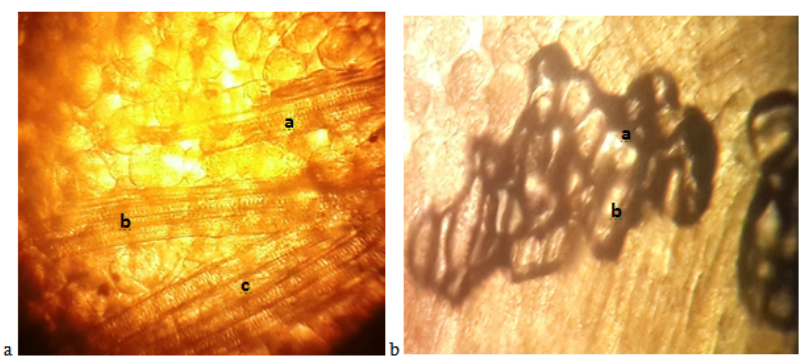

Figure 7. a) Valeriana officinalis rhizome with roots transverse section (Ashotavan), a-c-thickened net-like vessels, b) Valeriana officinalis root transverse section (Ashotavan). $a$ and b-stone cells.

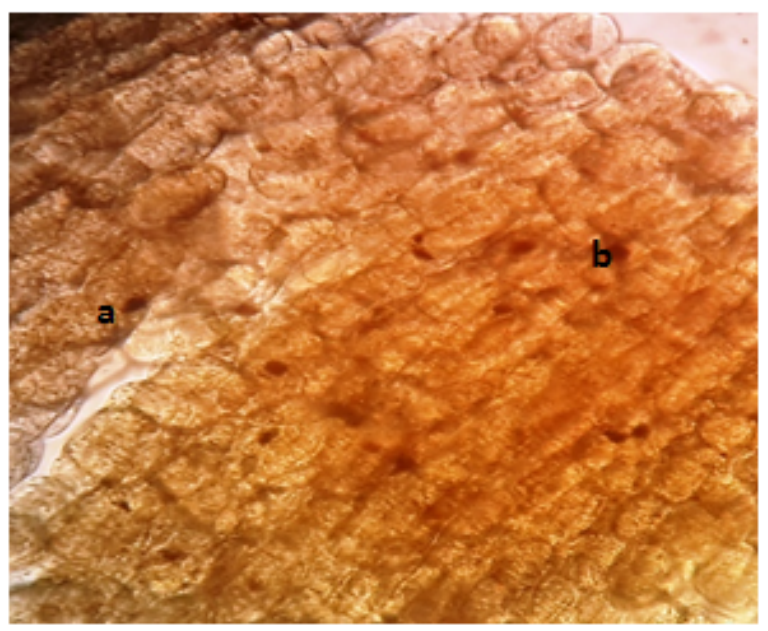

Figure 8. Valeriana officinalis rhizome transverse section (Ashotavan). a and b-drouses.

Table 1. The quality indices of Valeriana officinalis L. rhizome and roots cultivating in different regions of Armenia.

\begin{tabular}{llllcc}
\hline Plant name & Region & Extract (\%) & Volatile oil (\%) & Moisture (\%) & Total ash (\%) \\
\hline Valeriana officinalis & Aparan & 29 & 1.22 & 8 \\
\cline { 2 - 5 } & Ashotavan & 27 & 0.98 & 8.1 \\
\hline
\end{tabular}


The total ash in the raw material harvested from Aparan was $8 \%$, in the raw material from Ashotavan was $7.8 \%$. These marked indices didn't exceed the European pharmacopeia (12\% not over) standards. Considerably the moisture indices in the raw material cultivated from Aparan was $8 \%$, and in the raw material cultivated in Ashotavan was 8.1\% (Table 1) [29].

The qualitative and quantitative compositions of volatile oil cultivated from Valeriana officinalis L. climatized in Aparan and in Ashotavan were confirmed by gas chromatographymass spectrometry method (Figures 9 and 10).

In the result of the essential oil analysis derived from the raw material of Valerian officinalis L. cultivating in Aparan from invented 5 compounds, only bornyl acetate was identified, the quantity of which was $55.2 \%$ (Figure 9).

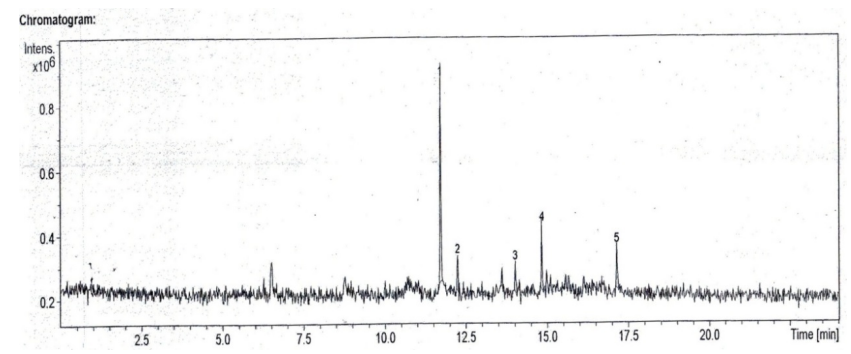

Figure 9. GC-MS analysis of volatile oil obtained from Valeriana officinalis rhizome with roots cultivated in Aparan. Identified substances: 1.Bornyl acetate.

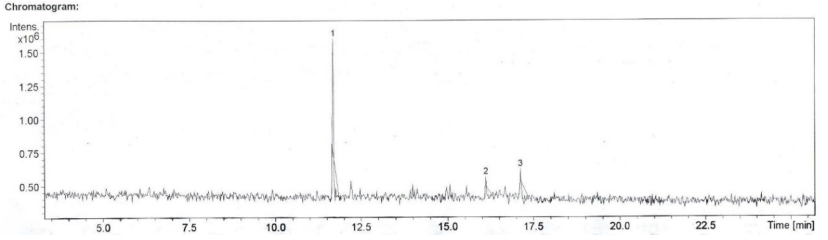

Figure 10. GC-MS analysis of volatile oil obtained from Valeriana officinalis rhizome with roots cultivated in Ashotavan. Identified substances: 1. Bornyl acetate.

In the essential oil of Valeriana officinalis L. cultivated in Ashotavan 3 compounds were invented, only bornyl acetate was identified. The quantity of which was 90. 7\% (Figure 10).

The analysis showed that in volatile oil of Valeriana officinalis L. climatized in Ashotavan and in Aparan the prevailing was bornyl acetate, the quantities of which were $55.2 \%$ and $90.7 \%$.

\section{Conclusion}

1. Anatomical-differentiative features of Valeriana officinalis L. rhizomes and roots cultivated in different regions of Armenia were defined.

2. Unlike the raw material cultivated in Aparan, in the preparation of raw material in Ashotavan stone cells are well seen, which proves that in mountainous zone the mechanical tissue is well developed, as well as drouses exist (sclereids).
3. In the result of the research confined the quality indices of Valeriana officinalis L. cultivated in Ashotavan and Aparan (volatile oil, the total of extracts, moisture, and total ash).

4. Bornyl acetate was identified in the volatile oil obtained from the raw material of Valeriana officinalis L. cultivated in Ashotavan and in Aparan, which was prevailed in the raw material cultivated in Ashotavan.

\section{References}

1. Jerome $\mathrm{S}$, Alexander $\mathrm{P}$, Isaac $\mathrm{S}$, Con $\mathrm{S}$, Andrew S. Herbal medicine for depression, anxiety and insomnia: a review of psychopharmacology and clinical evidence. Eur Neuropsychopharmacol J 2011; 21: 841-860.

2. Khom S, Baburin I, Timin E, Hohaus A, Trauner G, Kopp B, Hering S. Valerenic acid potentiates and inhibits GABA(A) receptors: molecular mechanism and subunit specificity. Neuropharmacol J 2007; 53: 178-187.

3. Leach MJ, Page AT. Herbal medicine for insomnia: a systematic review and meta-analysis. J Sleep Med Rev 2015; 24: 1-12.

4. Maroo N, Hazra A, Das T. Efficacy and safety of a polyherbal sedative-hypnotic formulation NSF-3 in primary insomnia in comparison to zolpidem: a randomized controlled trial. Ind J Pharmacol 2013; 45: 34-39.

5. Murphy K, Kubin ZJ, Shepherd JN, Ettinger RH. Valeriana officinalis root extracts have potent anxiolytic effects in laboratory rats. Phytomed Int $\mathrm{J}$ Phytother Phytopharmacol 2010; 17: 674-678.

6. Abhijit D, Amrita D. Phytotherapy against insomnia: extravagant claims or an alternative medicine? Pak J Biol Sci 2013; 16: 148-150.

7. Altarian H, Hachul H, Guttuso T, Phillips B. Treatment of chronic insomnia disorder in menopause: evaluation of literature. J Menopause 2015; 22: 674-684.

8. Bent S, Padula A, Moore D, Patterson M, Mehling W. Valerian for sleep: a systematic review and meta-analysis. Am J Med 2006; 119: 1005-1012.

9. Debra LB, Pamela JA, Brent AB, Dennis FM, Bassam IM, Beth IL, Kendrith MR, Robin TZ, Nguyet AL, Gauri GN, Timothy IM, Jeff AS, Charles LL. The use of Valeriana officinalis (Valerian) in improving sleep in patients who are undergoing treatment for cancer: a phase III randomized, placebo-controlled, double-blind study: NCCTG trial, N01C5. J Supp Oncol 2011; 9: 24-31.

10. Donath F, Quispe S, Diefenbach K, Maurer A, Fietze I, Roots I. Critical evaluation of the effect of valerian extract on sleep structure and sleep quality. Pharmacopsych J 2000; 33: 47-53.

11. Fernandez-San-Martin MI, Masa-Font R, Palacios-Soler L, Sancho-Gomez P, Calbo-Caldentey C, Flores-Mateo G. Effectiveness of Valerian on insomnia: a meta-analysis of randomized placebo-controlled trials. J Sleep Med 2011; 11: $505-511$. 


\section{cum Radicibus valerianae officinalis $L$.)}

12. Gallo L, Ramirez-Rigo M. V, Pina J, Palma S, Allemandi D, Bucala V. Valeriana officinalis dry plant extract for direct compression: preparation and characterization. Scienta Pharm J 2012; 80: 1013-1026.

13. Goonerate NS. Complementary and alternative medicine for sleep disturbances in older adults. Clin Geriatr Med J 2008; 24: 121-138.

14. Gromball J, Beschorner F, Wantzen C, Paulsen U, Burkart M. Hyperactivity, concentration difficulties and impulsiveness improve during seven weeks treatment with valerian root and lemon balm extracts in primary school children. Phytomed J 2014; 21: 1098-1103.

15. Nalaka SG. Complementary and alternative medicine for sleep disturbances in older adults. Clin Geriatr Med J 2008; 24: 121-138.

16. Pyle BW, Tran HT, Pickel B, Haslam TM, Gao Z, MacNevin G, Vederas JC, Kim SU, Ro DK. Enzymatic synthesis of valerena-4,7(11)-diene by unique sesquiterpene synthase from the valerian plant (Valeriana officinalis). FEBS J 2012; 279: 3136-3146.

17. Salter S, Brownie S. Treating primary insomnia-the efficacy of valerian and hops. Aus Fam Phys J 2010; 39: 433-437.

18. Sarris J, Byrne GJ. A systematic review of insomnia and complementary medicine. J Sleep Med Rev 2011; 15: 99-106.

19. Taibi DM, Vitiello MV, Barsness S, Elmer GW, Anderson GD, Landis CA. A randomized clinical trial of valerian fails to improve self-reported, polysomnographic and actigraphic sleep in older women with insomnia. Sleep Med J 2009; 10: 319-328.

20. Tariq SH, Pulisetty S. Pharmacotherapy for insomnia. Clin Geriatr Med 2008; 24: 93-105.

21. Waldschutz R, Klein P. The homeopathic preparation Neurexan vs. valerian for the treatment of insomnia: an observational study. Sci World J 2008; 8: 411-420.
22. Wang PC, Ran XH, Chen R, Luo HR, Ma QY, Liu YQ, $\mathrm{Hu}$ JM, Huang SZ, Jiang HZ, Chen ZQ, Zhou J, Zhao YX. Sesquiterpenoids and lignans from roots of Valeriana officinalis L.. Chem Biodivers J 2011; 8: 1908-1913.

23. Wheatley D. Medicinal plants for insomnia: a review of their pharmacology, efficacy and tolerability. Psychopharmacol J 2005; 19: 414-421.

24. Herrera-Arellano A, Luna-Villegas G, Cuevas-Uriostegui ML, Alvarez L, Vargas-Pineda G, Zamilpa-Alvarez A, Tortoriello J. Polysomnographic evaluation of the hypnotic effect of Valeriana edulis standardized extract in patients suffering from insomnia. J Planta Medica 2001; 67: 695-699.

25. Houghton PJ. The scientific basis for the reputed activity of Valerian. J Pharm Pharmacol 1999; 51: 505-512.

26. Jacobs BP, Bent S, Tice JA, Blackwell T, Cummings SR. An internet-based randomized, placebo-controlled trial of kava and valerian for anxiety and insomnia. Med (Baltimore) J 2005; 84: 197-207.

27. WHO guidelines on good agricultural and collection practices (GACP) for medicinal plants. WHO Geneva 2003; 13-16.

28. Quality control methods for herbal materials. WHO 2011; 11-23, 37-41.

29. European Pharmacopoeia (8th Edn.). 2013; 1413-1417.

\section{*Correspondence to}

Hovhannisyan VG

Department of Pharmacognosy

Yervan State Medical University after M. Heratsi

Armenia 